\title{
Antibacterial and anti-biofilm activity of mouthrinses containing cetylpyridinium chloride and sodium fluoride
}

\author{
Joe Latimer ${ }^{1}$, Jodie L Munday ${ }^{1}$, Kara M Buzza ${ }^{1}$, Sarah Forbes ${ }^{1}$, Prem K Sreenivasan ${ }^{2}$ and Andrew J McBain ${ }^{\text {* }}$
}

\begin{abstract}
Background: Cetylpyridinium chloride (CPC) and sodium fluoride augment oral hygiene by inactivating bacteria and inhibiting enamel demineralisation, respectively. However, there are few reports in the literature documenting the antibacterial efficacy of their combined use in mouthrinses. We have used six experimental systems to compare the antibacterial effects of mouthrinses containing $0.075 \%$ CPC (test rinse, TR) or $0.075 \%$ CPC with sodium fluoride (test fluoride rinse, TFR).
\end{abstract}

Results: Effects against planktonic bacteria were determined using viable counting (for Streptococcus mutans and salivary bacteria), a redox dye (for Actinomyces viscosus and salivary bacteria) and viable counting (for ex vivo oral rinses). Effects against saliva-derived biofilms were quantified using confocal microscopy and differential viable counting. Inhibition of biofilm formation was evaluated by pre-treating hydroxyapatite coupons with mouthrinses prior to inoculation. Otherwise-identical controls without CPC (control rinse and control fluoride rinse, CR and CFR, respectively), were included throughout. Compared to the controls, TFR and TR demonstrated significant antimicrobial effects in the redox assays, by viable counts (>3 log reductions) and in oral rinse samples (>1.25 log reductions, $p<0.05)$. TFR and TR also significantly reduced the viability of oral biofilms. Pre-treatment of hydroxyapatite with TFR and TR significantly inhibited biofilm formation (>3 log difference, $p<0.05$ ). Overall, there were no consistent differences in the activities of TR and TFR.

Conclusions: Sodium fluoride did not influence the antibacterial and anti-biofilm potency of CPC-containing formulations, supporting the combined use of CPC and sodium fluoride in mouthrinses to control oral bacteria and protect tooth enamel.

\section{Background}

Dental caries is a major public health problem throughout the world $[1,2]$. Extensive research has indicated that the major cause of caries is the acidification of tooth surfaces following fermentation of dietary sugars by cariogenic bacteria which accumulate on the surfaces of teeth within dental plaque [3]. If the $\mathrm{pH}$ of the tooth surface drops below a critical value, thought to be approximately 5.5 , enamel will begin to demineralise [4] eventually resulting in the formation of carious lesions. Commonly-implicated causative bacteria include Streptococcus mutans and homofermentative lactobacilli

\footnotetext{
* Correspondence: andrew.mcbain@manchester.ac.uk

'Manchester Pharmacy School, The University of Manchester, Oxford Road, Manchester M13 9PT, UK

Full list of author information is available at the end of the article
}

(as reviewed by Marsh [5]). Actinomyces species are also believed to be significant contributors, particularly to root caries [6-8]. Thorough mechanical removal of plaque twice daily with a fluoride-containing toothpaste is a commonly-taught method of caries prevention. However, studies show that incidence of dental caries remains high $[9,10]$, suggesting that such regimens are commonly not strictly adhered to.

Mouthrinses containing antibacterial compounds may augment routine oral hygiene measures by inactivating bacteria remaining in the mouth after brushing [11-13] and by inhibiting their regrowth and reattachment to tooth surfaces. A variety of antibacterial formulations have been produced, incorporating actives such as chlorhexidine, ethanol and essential oils, with differing levels of reported antibacterial effects and oral substantivity [14-18]. 
Cetylpyridinium chloride (CPC), a cationic quaternary ammonium compound, has been demonstrated in clinical and in vitro studies to inactivate oral bacteria, reducing plaque and gingivitis [19-25].

It is believed that the combined use of fluoride with an antibacterial compound is beneficial in the prevention of caries [26] due to simultaneous strengthening of enamel and inactivation of bacteria. Antibacterial agents inactivate oral bacteria, decreasing the bacterial burden, thereby reducing net acid production and moderating the $\mathrm{pH}$ drop following sugar consumption (as reviewed by Gilbert et al. [27]). Fluoride acts primarily by decreasing the $\mathrm{pH}$ at which enamel demineralizes. Tooth enamel is composed of crystals of hydroxyapatite, a mineral form of calcium apatite $\left(\mathrm{Ca}_{10}\left(\mathrm{PO}_{4}\right)_{6}(\mathrm{OH})_{2}\right)$. Free fluoride ions can adsorb to hydroxyapatite crystals, inhibiting demineralisation during acid challenge and enhancing remineralisation when $\mathrm{pH}$ levels subsequently rise [28, 29]. Fluoride may also reduce acid production by inhibiting bacterial glucose metabolism and thus reducing acidogenesis and the associated enrichment of aciduric species in plaque [30]. There have been recent concerns that the use of mouthrinses immediately following brushing may remove residual fluoride [31]. Incorporation of fluoride into mouthrinses may compensate for this loss by effectively delivering fluoride which is then retained in saliva post-rinsing [32, 33].

Clinical research has demonstrated that experimental mouthrinse formulations containing both sodium fluoride and $\mathrm{CPC}$ are effective in reducing the accumulation of supragingival plaque bacteria [24] and are as effective as a fluoride-only rinse in inhibiting enamel demineralisation in vitro [34]. This suggests that CPC does not interfere with the effects of fluoride. However, no comprehensive studies are available in the literature that have investigated the antibacterial efficacy of CPC-based mouthrinses with or without added fluoride. Further, the activities of formulations and active ingredients are commonly assessed using a single methodological approach or selected species of interest [35-38]. The current investigation therefore used multiple approaches to compare the antibacterial efficacy of mouthrinses formulated with $0.075 \% \mathrm{CPC}$, alone or in combination with $225 \mathrm{ppm}$ sodium fluoride. Activities against planktonic bacteria were assessed using pure cultures of cariogenic species, oral bacterial consortia and ex-situ human oral samples. Activities against established plaques and on the inhibition of plaque formation were also assessed.

\section{Results}

Test formulations rapidly inactivate established cultures of oral bacteria

Bactericidal effects were assessed by viable counts following exposure to test rinses. These experiments revealed that TR and TFR caused $6.2 \log _{10}$ and $6.9 \log _{10}$ reductions in viable counts of Streptococcus mutans, respectively, compared to their respective controls (Fig. 1). A modest but significant increase in bactericidal efficacy was observed in the formulation containing fluoride in comparison with the non-fluoridated rinse. Significant effects of both formulations were also observed against mixed salivary bacteria $\left(6.2 \log _{10}\right.$ and $4.6 \log _{10}$ reductions for TR and TFR respectively), but with significantly increased efficacy observed in the non-fluoridated formulation.

The short-term effects of test rinses on the redox activity of established cultures of oral bacteria were assessed using a resazurin-based redox dye. Both of the test rinses caused significant reductions in the viability of $A$. viscosus and mixed salivary bacteria within $10 \mathrm{~min}$ (Fig. 2.). This effect was more marked in cultures of $A$. viscosus than salivary bacteria. There were no significant differences between the effects of TR and TFR. There was no significant difference in bacterial viability following treatment with the control rinses.

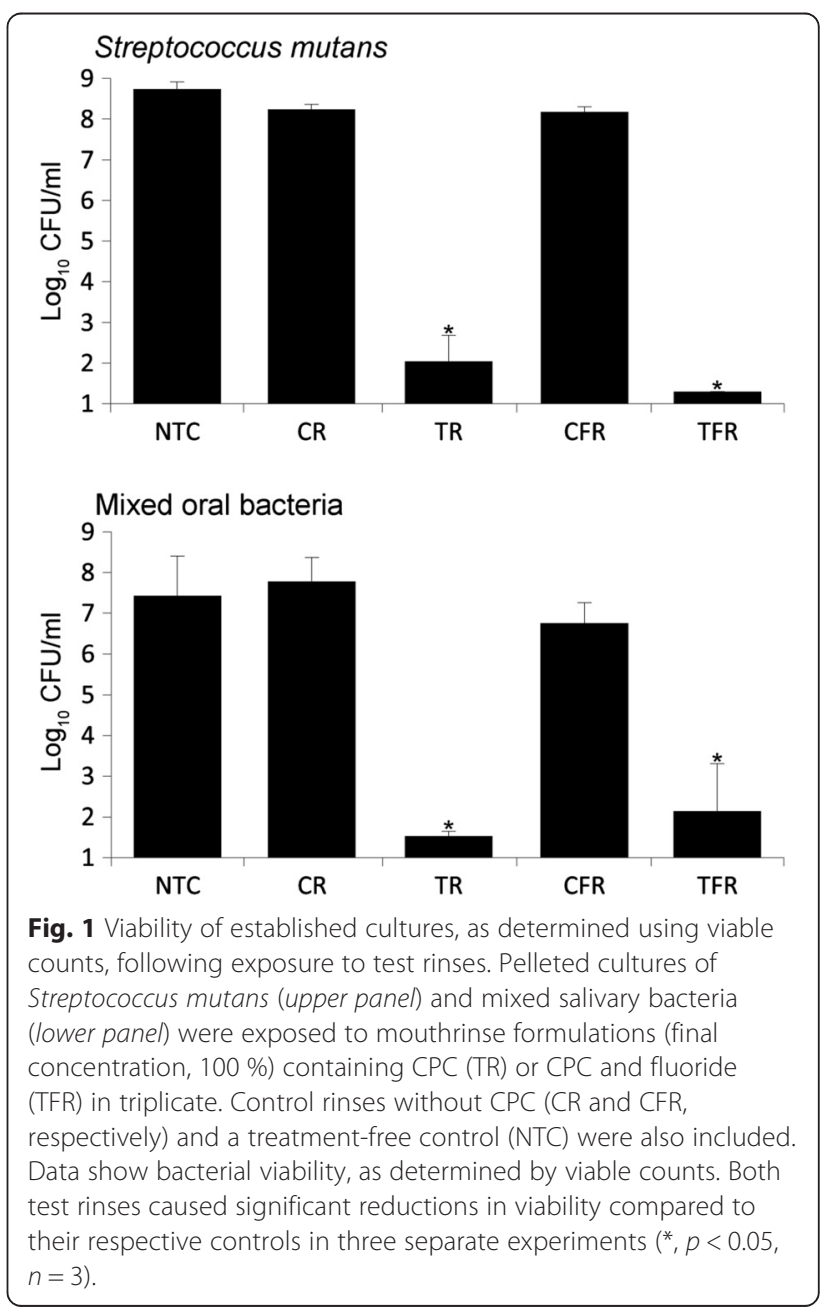




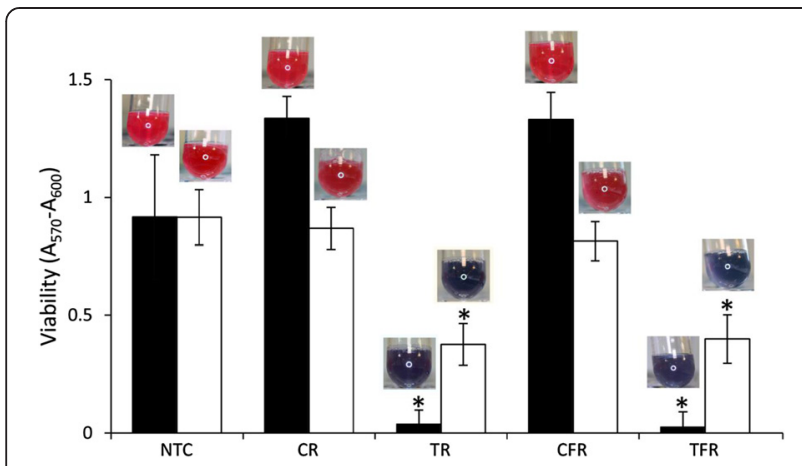

Fig. 2 Viability of established cultures, as determined using a redox dye, following exposure to test rinses. Cultures of Actinomyces viscosus (black bars) and mixed salivary bacteria (white bars) were exposed to mouthrinse formulations (final concentration, $10 \% \mathrm{v} / \mathrm{v}$ ) containing CPC (TR) or CPC and fluoride (TFR) in triplicate. Control rinses without CPC (CR and CFR, respectively) and a treatment-free control (NTC) were also included. Data show mean viability (background-corrected $A_{570}-A_{600}$ ), as determined with a redox indicator dye. Representative images are included. Both test rinses caused significant reductions in viability compared to their respective controls in three separate experiments $\left(^{*}, p<0.05, n=3\right.$ )

\section{Test formulations inactivate bacteria from ex vivo oral} rinse samples

The effects of test rinses on the viability of ex situ human oral bacteria were assessed by exposing oral rinse samples from healthy volunteers, ex vivo, to test formulations (Table 1). TR and TFR both caused greater than a1.0 Log reduction in comparison to their respective controls. There was no significant difference between the control rinses and the untreated control. There was no significant difference in the viability of samples treated with the fluoridated and nonfluoridated rinses.

Table 1 Viability of human oral rinse samples following ex-vivo exposure to test rinses

\begin{tabular}{llll}
\hline Treatment & $\begin{array}{l}\text { Mean counts ( } \log _{10} \mathrm{Cfu} / \mathrm{ml} ; \\
\text { SDs are given in parenthesis) }\end{array}$ & $\begin{array}{l}\log _{10} \text { difference } \\
\text { from control }\end{array}$ & $\begin{array}{l}P \text { value } \\
\text { (vs control) }\end{array}$ \\
\hline NTC & $7.92(0.25)$ & 0.16 (vs CR) & 0.34 \\
& & -0.094 (vs CFR) & 0.64 \\
CR & $8.08(0.25)$ & na & na \\
TR & $6.72(0.63)$ & 1.37 (vs CR) & 0.02 \\
CFR & $7.64(0.50)$ & na & na \\
TFR & $6.36(1.1)$ & 1.27 (vs CFR) & 0.04 \\
\hline
\end{tabular}

Oral rinse samples from five healthy volunteers were exposed to mouthrinse formulations (final concentration, $5 \% \mathrm{v} / \mathrm{v}$ ) containing CPC (TR) or CPC and fluoride (TFR). Control rinses without CPC (CR and CFR, respectively) and a treatment-free control (NTC) were also included. Mean viable count data are shown. Both test rinses caused significant reductions in viability compared to their respective controls in samples from five volunteers $\left({ }^{*}, p<0.05, n=5\right)$. na, not applicable
Test formulations inactivate in vitro oral biofilms

Plaques were cultivated under anaerobic conditions to reflect the anoxic environments of these complex communities. Plaques were visualised by confocal microscopy following single exposures of test rinses, using a viability stain containing a combination of SYTO9 and propidium iodide to differentiate viable and non-viable cells. Images and resulting depth profiles revealed that test rinses caused marked reductions in the viability of oral biofilms; even at depth, as indicated by a distinct increase in the relative levels of red fluorescence through their depths (Fig. 3). The appearance and profiles of the biofilms exposed to the control rinses resembled much more closely those of the treatment-free control, exhibiting mainly green fluorescence with small areas of nonviable mass which were localised predominantly in the centres of larger clusters.

The effects of test rinses on the viability of biofilms formed by salivary bacteria were also compared by dosing biofilms twice daily for four days (Fig. 4). The viability of aerobes/facultative anaerobes, total anaerobes and Gram-negative anaerobes was assessed by viable counting. TR caused significant viability reductions in all groups compared to CR $(p<0.05)$. TFR also caused significant reductions compared to its respective control, CFR, except against total anaerobes. There was no significant difference between the effects of $C R$ and the treatment-free controls. CFR, however, did cause viability reductions and in the case of aerobes, CFR-treated plaques were significantly less viable than a treatmentfree control. There was no significant difference between TR and TFR except against Gram-negative anaerobes, where TFR was marginally more effective.

\section{Pre-treatment of hydroxyapatite inhibits biofilm growth}

Hydroxyapatite surfaces were pre-exposed to test rinses to assess the effect on subsequent biofilm growth (Fig. 5). Treatment with TR and TFR resulted in large differences in biofilm density compared to their respective controls (3.1 and 4.7logs, respectively, $p<0.01$ ). There was no significant difference between the fluoridated and nonfluoridated rinses.

\section{Discussion}

The use of mouthrinses reportedly augments oral hygiene regimens based on regular brushing [12] and is believed to offer enhanced protection against dental caries, particularly when recommended oral healthcare regimens are not strictly adhered to [26]. The incorporation of sodium fluoride into antibacterial mouthwash formulations may further enhance caries control, especially post-brushing, when rinsing with water or a nonfluoridated mouthrinse can remove potentially beneficial residual fluoride [33]. In vitro assessments of the activity 

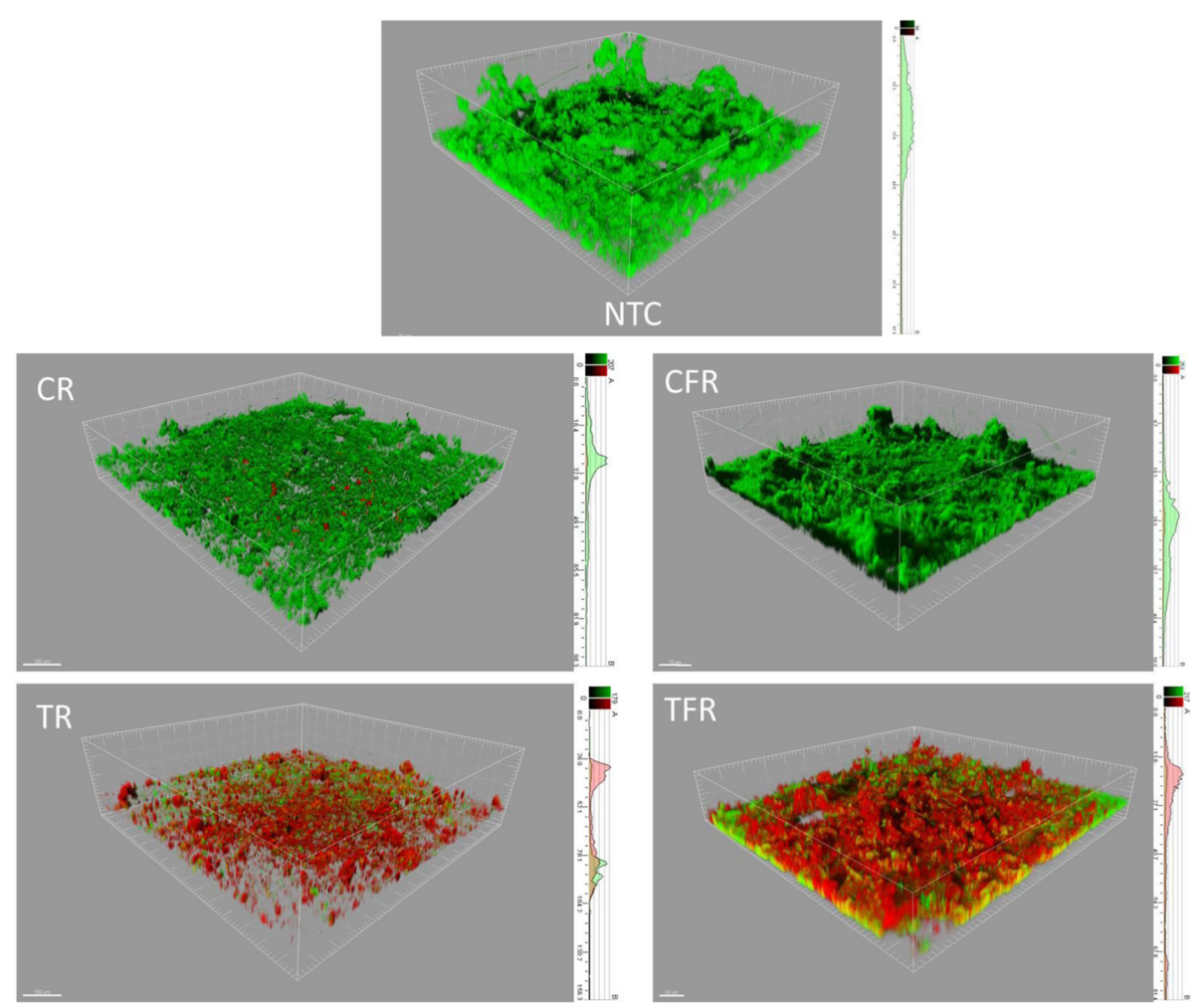

Fig. 3 Confocal microscopy of oral biofilms following exposure to test rinses. Biofilms were cultivated on hydroxyapatite surfaces inoculated with saliva and exposed to mouthrinse formulations (final concentration, $100 \%$ ) containing CPC (TR) or CPC and fluoride (TFR). Control rinses without CPC (CR and CFR, respectively) and a treatment-free control (NTC) were also included. Biofilms were then treated with a fluorescent viability stain and visualised by confocal microscopy. Three-dimensional projections show representative images of plaques and two-dimensional plots show representative depth profiles plotted through the deepest section of biofilm. Red, non-viable mass; green, viable mass. Higher proportions of red fluorescence among biofilms treated with test rinses indicate widespread inactivation of bacteria through their depths. Each grid represents a $776.5 \mu \mathrm{m}^{2}$ area of biofilm, each large grid square representing $51.77 \mu \mathrm{m}^{2}$. Depth profiles measure 97.7, 98.3, 58.0, 156.3 and $81.4 \mu \mathrm{m}$ for NTC, CR, CFR, TR and TFR, respectively

of mouthwash formulations are instructive, provided that a comprehensive assessment is made. The current investigation therefore employed six distinct methods to assess the antibacterial efficacy of two mouthrinse formulations, one containing $0.075 \% \mathrm{CPC}$ (TR) and another with $0.075 \%$ CPC and $250 \mathrm{ppm}$ sodium fluoride (TFR). The methods varied with respect to the test bacteria used, exposure times, the concentrations of the formulations and the types of outcome that were evaluated. Biofilms were cultured under anaerobic conditions in order to replicate the anoxic conditions extant in mature plaques [39].

In terms of mouthrinse effects on bacteria in planktonic culture, direct exposure of populations in this mode of growth indicated that large bactericidal effects occurred following short-term exposures to undiluted mouthrinses reflecting oral concentrations during rinsing in vivo, and provides a useful indication of the ability of the formulations to rapidly inactivate bacteria. Two test populations were used; a pure culture of the cariogenic bacterium S. mutans and a mixed culture of oral bacteria derived from saliva. Whilst both $S$. mutans cultures and mixed populations of oral bacteria were significantly inactivated by both test formulations, the inclusion of mixed populations is of value because growth in multi-species communities, even without biofilm formation, may decrease bacterial susceptibility. The resazurin dye-based method was used to assess measured metabolic effects of lower concentrations of test formulations on dense populations of mixed oral bacteria or pure cultures of Actinomyces viscosus within $10 \mathrm{~min}$. of exposure. These concentrations reflect residual levels of mouthrinse that might be expected to remain in the mouth following rinsing. Furthermore, this rapid method is relatively simple to perform and lends itself to highthroughput analysis, particularly since results correlate well with other approaches. The ex vivo test also assessed exposures to a lower concentration of test rinse, but this approach used fresh samples of oral bacteria isolated directly from human volunteers. These data showed good reproducibility between five volunteers, indicating that such techniques may provide useful preliminary data for larger clinical studies. 


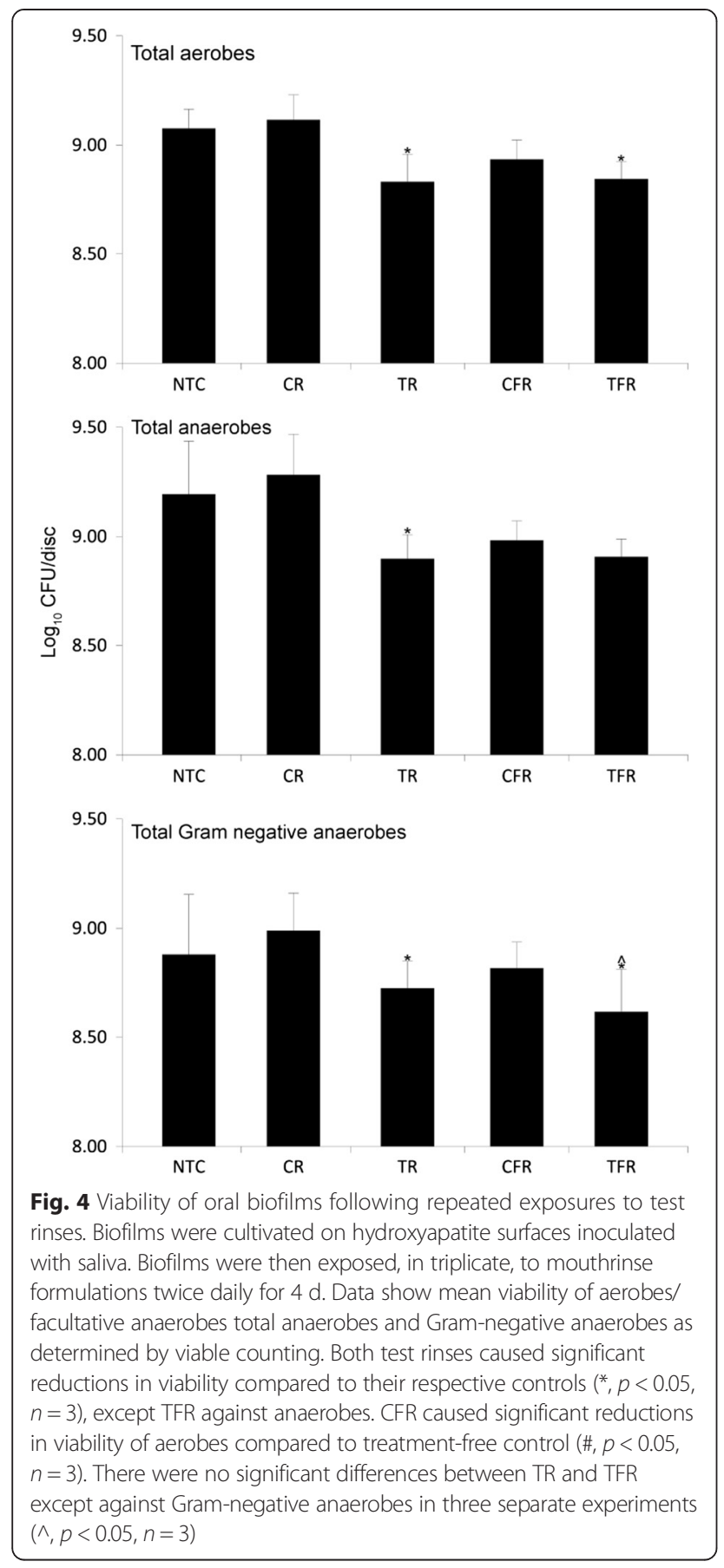

Antibacterial effects on biofilms were determined using three methods: i) Profiling by confocal microscopy $[40,41]$, which enabled the visualisation of cellular viability through plaque biofilms following a single exposure. This technique facilitates analysis of the spatial distribution of viable biomass within intact plaque. The creation of intensity plots in the $\mathrm{z}$ axis, although not necessarily representative of the thickness of the overall biofilm, indicates the extent of penetration of the antimicrobial compound through the sample. It is notable

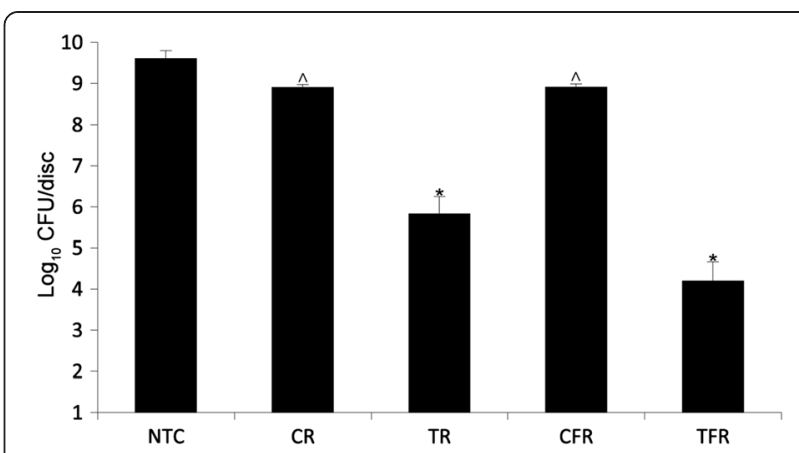

Fig. 5 Biofilm growth on hydroxyapatite surfaces pre-exposed to test rinses. Hydroxyapatite discs were soaked in mouthrinse formulations (final concentration, $100 \%$ ) containing CPC (TR) or CPC and fluoride (TFR). Control rinses without CPC (CR and CFR, respectively) and a treatment-free control (NTC) were also included. Six replicate discs for each treatment group were included. Biofilms were then cultivated on pre-exposed discs and mean total anaerobes were enumerated by viable counting. Surfaces exposed to both test rinses supported significantly less biofilm growth than their respective negative controls in six separate experiments $\left({ }^{*}, p<0.05, n=6\right)$. Pre-exposure to control rinses also resulted in less dense biofilms, although this effect was modest $(\wedge, p<0.05, n=6)$

that, even in the depths of larger biofilms clusters, considerable bacterial inactivation is apparent. This highlights the utility of confocal depth profiling versus epifluorescence microscopy, which provides a top-down view of overall biofilms viability. ii) Viable counting of treated plaques was also utilised and determines changes in the viability of different functional groups of bacteria in similarly-cultured plaques. Such changes can be quantified following multiple exposures, revealing longer-term effects of test formulations. iii) The activity of test formulations was also assessed by pre-treating hydroxyapatite surfaces prior to inoculation. Data thus generated indicate whether components of test formulations adsorbed onto surfaces are able to inhibit cell attachment or biofilm maturation, with obvious relevance to oral hygiene.

CPC-containing test rinses with (TFR) and without (TR) fluoride consistently and significantly inactivated bacteria in planktonic, ex-vivo and biofilm models. TR and TFR were both highly bactericidal against cultures of the cariogenic bacteria $S$. mutans and A. viscosus, against salivary oral bacteria, and against oral rinse samples from human volunteers. Both mouthrinses caused marked and significant viability losses even at concentrations of $5 \%$, suggesting that residual levels of test rinse may exhibit continued efficacy after rinsing.

Single and multiple exposures of plaque biofilms to both test rinses caused marked viability changes; confocal microscopy revealed extensive viability reductions in three dimensions and viable counting showed reductions in all bacterial groups tested. Both test rinses displayed a significant biofilm-inhibitory effect when used 
to pre-treat hydroxyapatite surfaces although it remains to be determined whether attachment, maturation or cell growth rate was inhibited.

With respect to the effect of fluoride on the efficacy of CPC-containing rinses, TFR and TR generally exhibited equivalent activities. This indicates that the presence of fluoride at $225 \mathrm{ppm}$ does not reduce the antibacterial efficacy of mouthrinse formulations containing CPC. Combined with previous findings that incorporation of CPC does not affect the ability of fluoride to inhibit demineralisation, these data support the combined use of $\mathrm{CPC}$ and fluoride in mouthrinse formulations.

\section{Conclusions}

CPC-containing mouthrinses, with and without fluoride, exhibited significant antibacterial efficacy against oral bacteria in planktonic and biofilm modes, and at varying concentrations. Fluoridated and non-fluoridated CPC rinses generally exhibited equivalent activities, supporting the combined use of CPC and sodium fluoride in mouthrinse formulations.

\section{Methods}

\section{Saliva samples}

In all experiments where saliva was used as inoculum to generate planktonic cultures of oral bacteria or in vitro dental plaques; or where saliva was analyzed following ex vivo exposure, the volunteers ( $2 \mathrm{M}, 3 \mathrm{~F}$ without active cares or periodontal disease), were instructed to brush as normal twice a day with a standard fluoride toothpaste without additional oral hygiene for seven days prior to saliva collection. Without exception, saliva was used within $1 \mathrm{~h}$ of collection.

\section{Test formulations}

Two mouthrinse formulations containing $0.075 \%$ cetylpyridinium chloride $(\mathrm{CPC})$ with or without sodium fluoride (225 ppm) (TFR and TR, respectively) were tested in this study. Otherwise-identical controls without $\mathrm{CPC}$ were also included (with or without sodium fluoride, CFR and CR, respectively).

\section{Direct planktonic exposures}

Cultures $(20 \mathrm{ml})$ of $S$. mutans or salivary bacteria (fresh human saliva diluted 1:100 in Wilkins Chalgren broth and incubated immediately after collection), were grown statically in Wilkins Chalgren broth at $37{ }^{\circ} \mathrm{C}$ to $\mathrm{OD}_{600}$ 0.8 aerobically. Aliquots $(1 \mathrm{ml})$ were centrifuged, the pellet resuspended in test formulations $(100 \%, 1 \mathrm{ml})$ and incubated at room temperature with shaking for $30 \mathrm{~s}$. Suspensions were centrifuged and washed twice in phosphate buffered saline (PBS; $0.01 \mathrm{M}$ phosphate, $0.0027 \mathrm{M}$ $\mathrm{KCl}, 0.137 \mathrm{M} \mathrm{NaCl}, \mathrm{pH}$ 7.4). Serial dilutions were performed in PBS, spread-plated on Wilkins Chalgren agar and incubated aerobically at $37^{\circ} \mathrm{C}$ for viable counts.

\section{Immediate effects on bacterial metabolism}

The effects of test rinses on the redox activity of oral bacteria was assessed using a resazurin-based dye, in an adaptation of a method initially described by Shiloh and co-workers [42]. Cultures $(n=3)$ of $A$. viscosus or salivary bacteria (saliva diluted 1:100 and cultured aerobically at $37{ }^{\circ} \mathrm{C}$ to $\mathrm{OD}_{600} 0.8$ in tryptone soy broth, which was shown to be the most suitable medium in validation experiments (data not shown)) were used. These were exposed to test mouthrinses for 10s (final concentration, $10 \%$ ) before immediately adding alamarBlue ${ }^{\mathrm{Tx}}$ viability indicator (Life Technologies, Paisley, U.K.) to a final concentration of $6 \% \mathrm{v} / \mathrm{v})$. Following incubation at room temperature for $10 \mathrm{~min}$, cultures were examined visually and spectrophotometrically (mean background-corrected $\mathrm{A}_{570}-\mathrm{A}_{600}$ values) to assess viability.

\section{Ex vivo tests}

Healthy volunteers $(n=5,2$ males and 3 females, age range 24-35) were asked to refrain from oral hygiene for $12 \mathrm{~h}$ before sampling. Ex vivo samples were then acquired by asking volunteers to rinse their mouths with $10 \mathrm{ml}$ of natural mineral water (Sainsbury's, London, UK), expectorate into a sterile test tube, brush their tongues with a new soft brush and agitate in the water, to generate suspensions containing oral bacteria. Mouthrinse formulations $(500 \mu \mathrm{l})$ were added to each suspension $(10 \mathrm{ml}$, final concentration, $5 \% \mathrm{v} / \mathrm{v})$ and incubated for $1 \mathrm{~min}$ before performing serial dilutions and spreadplating on Wilkins Chalgren agar for viable counts.

\section{Confocal microscopy of dosed biofilms}

Optical sectioning of viability distributions in plaque was carried out using techniques developed by Netuschil et al. [43] and Hope and co-workers [40] and adapted by Ledder et al. [41]. In the current study, plaque biofilms were grown and maintained in a hydroxyapatite disc biofilm reactor as previously described [44] and adapted as follows: Wilkins Chalgren broth containing $0.25 \%$ porcine mucin and $1 \%$ sucrose $(0.5 \mathrm{ml})$ was dispensed into a sterile 24-well tissue culture plate. The broth was then inoculated with saliva $(0.5 \mathrm{ml})$. Sterile hydroxyapatite discs were placed in the wells and incubated anaerobically for $24 \mathrm{~h}$ at $37^{\circ} \mathrm{C}$. Biofilms were removed from the anaerobic workstation and exposed once at room temperature to test mouthrinses or sterile water (notreatment control) for $2 \mathrm{~min}$. All plaques were gently rinsed with sterile water to remove excess treatments, stained with a combination of fluorescent dyes i.e. propidium iodide and SYTO9 (Live/Dead stain) and evaluated by confocal scanning laser microscopy (TCS SP5, Leica 
Microsystems, Milton Keynes, UK) for microbial viability profiling. The entire disc was evaluated visually and representative images (1 per disc) were captured with LAS AF software (Leica), covering the entire depth of the biofilm. Further processing, quantification and depth profiling was performed using Imaris (Bitplane AG, Zurich, Switzerland).

\section{Plaque viability tests}

Plaque biofilms were maintained in a hydroxyapatite disc biofilm reactor as described above prior to the following dosing regimen: Twice daily for 2 min., discs were transferred to fresh plates containing test rinse or sterile water $(2 \mathrm{ml})$. In order to maximise microbial diversity, the discs were then transferred to a fresh plate containing broth (morning) or broth and fresh salivary inoculum (evening). This dosing regimen continued for 4 days in order to broadly simulate the repeated exposure and regrowth cycle which would be experienced by plaque in-vivo. Following the final dosing, discs were aseptically removed, gently immersed in sterile PBS to remove loosely attached organisms, added to pre-reduced, halfstrength thioglycollate medium and vortexed thoroughly for $1 \mathrm{~min}$. Samples were serially diluted and appropriate dilutions $(0.1 \mathrm{ml})$ were plated in triplicate onto a variety of selective and non-selective media. These media were as follows; Wilkins-Chalgren agar (incubated anaerobically for total anaerobes or aerobically for total aerobes and facultative anaerobes) and Wilkins-Chalgren agar with gram-negative supplement (total gram-negative anaerobes). Inoculated agars were incubated in an anaerobic chamber (MG1000 workstation, Don Whitley Scientific, UK) at $37{ }^{\circ} \mathrm{C}$ for up to $5 \mathrm{~d}$. Aerobes were incubated aerobically for up to $3 \mathrm{~d}$. Three biological replicates were included, each analysed in triplicate.

\section{Inhibition of bacterial attachment to hydroxyapatite}

Hydroxyapatite discs $(n=6)$ were incubated statically at room temperature in test rinses or sterile water $(1 \mathrm{ml}$ in the wells of a 12-well tissue culture plate) for $24 \mathrm{~h}$. Discs were then rinsed briefly in distilled water and transferred to a sterile 24-well tissue culture plate with Wilkins Chalgren broth containing $0.25 \%$ porcine mucin and $1 \%$ sucrose $(0.5 \mathrm{ml})$. Medium was then inoculated with saliva $(0.5 \mathrm{ml})$. Plaques were incubated anaerobically at $37^{\circ} \mathrm{C}$ for $48 \mathrm{~h}$, changing the medium at $24 \mathrm{~h}$. Following this growth phase, discs were rinsed and suspended in half-strength thioglycollate medium, before performing serial dilutions and spread-plating on Wilkins Chalgren agar for viable counts of total anaerobes as described above.

\section{Ethics and consent}

Advice was taken from the Chair of a University of Manchester Research Ethics Committee regarding the correct procedures associated with the use of human oral rinse samples for the ex vivo experiments. The committee granted exemption from formal ethics approval due to the nature of the work but as advised, informed consent was obtained from all volunteers and all samples were collected anonymously.

\section{Data analysis}

All data are shown as mean values plus/minus standard deviations. Statistical significance between data sets was calculated using Student's $t$-test with significance reported at $\leq 0.05$ (Microsoft Excel 2010).

\section{Abbreviations}

CPC: Cetylpyridinium chloride; TR: Test rinse; TFR: Test fluoride rinse; CR: Control rinse; CFR: Control fluoride rinse; NTC: Treatment free control.

\section{Competing interests}

This research was funded by a grant to AJM from Colgate Palmolive Company.

PKS is an employee of Colgate Palmolive.

\section{Authors' contributions}

$J$, PKS and AJM contributed to the conception and design of the study. $J$, $J \mathrm{LM}, \mathrm{KB}$ and SF carried out the laboratory experiments. JL, JLM, KMB, PKS and AJM contributed to data analysis and interpretation. $J \mathrm{~L}$ and AJM drafted the manuscript. All authors read the final manuscript, with final approval from AJM.

\section{Acknowledgment}

This research was supported by an unrestricted grant from Colgate Palmolive Company.

\section{Author details}

${ }^{1}$ Manchester Pharmacy School, The University of Manchester, Oxford Road, Manchester M13 9PT, UK. ${ }^{2}$ Colgate-Palmolive Technology Center, Piscataway, NJ, USA.

Received: 10 April 2015 Accepted: 5 August 2015

Published online: 21 August 2015

\section{References}

1. Bagramian RA, Garcia-Godoy F, Volpe AR. The global increase in dental caries. A pending public health crisis. Am J Dent. 2009;22(1):3-8.

2. Richards D. Oral diseases affect some 3.9 billion people. Evid Based Dent. 2013;14(2):35.

3. Marsh PD. Microbiology of dental plaque biofilms and their role in oral health and caries. Dent Clin N Am. 2010;54(3):441-54

4. Stephan RM. Intra-Oral Hydrogen-Ion Concentrations Associated With Dental Caries Activity. J Dent Res. 1944;23(4):257-66.

5. Marsh PD. Dental plaque as a biofilm and a microbial community implications for health and disease. BMC Oral Health. 2006;6 Suppl 1:S14.

6. Bowden $\mathrm{GH}$, Ekstrand J, McNaughton B, Challacombe SJ. Association of selected bacteria with the lesions of root surface caries. Oral Microbiol Immunol. 1990:5(6):346-51.

7. Bowden $\mathrm{GH}$. Microbiology of root surface caries in humans. J Dent Res. 1990;69(5):1205-10.

8. Jiang $W$, Zhang J, Chen $\mathrm{H}$. Pyrosequencing analysis of oral microbiota in children with severe early childhood dental caries. Curr Microbiol. 2013;67(5):537-42.

9. Petersen PE, Bourgeois D, Ogawa H, Estupinan-Day S, Ndiaye C. The global burden of oral diseases and risks to oral health. Bull World Health Organ. 2005;83(9):661-9.

10. Bernabe E, Sheiham A. Age, period and cohort trends in caries of permanent teeth in four developed countries. Am J Public Health. 2014;104(7):e115-21.

11. Quintas V, Prada-Lopez I, Prados-Frutos JC, Tomas I. In situ antimicrobial activity on oral biofilm: essential oils vs. $0.2 \%$ chlorhexidine. Clin Oral Investig. 2014;19(1):97-107. 
12. Hoffmann T, Bruhn G, Richter S, Netuschil L, Brecx M. Clinical controlled study on plaque and gingivitis reduction under long-term use of low-dose chlorhexidine solutions in a population exhibiting good oral hygiene. Clin Oral Investig. 2001;5(2):89-95.

13. Barnett ML. The rationale for the daily use of an antimicrobial mouthrinse. J Am Dent Assoc. 2006;137(Suppl):16S-21.

14. Ennibi O, Lakhdar L, Bouziane A, Bensouda Y, Abouqal R. Chlorhexidine alcohol base mouthrinse versus Chlorhexidine formaldehyde base mouthrinse efficacy on plaque control: double blind, randomized clinical trials. Med Oral Patol Oral Cir Bucal. 2013;18(1):e135-9.

15. Marchetti E, Mummolo S, Di Mattia J, Casalena F, Di Martino S, Mattei A, et al. Efficacy of essential oil mouthwash with and without alcohol: a 3-day plaque accumulation model. Trials. 2011;12:262.

16. Singh A, Daing A, Dixit J. The effect of herbal, essential oil and chlorhexidine mouthrinse on de novo plaque formation. Int J Dent Hyg. 2013;11(1):48-52.

17. Narayan A, Mendon C. Comparing the effect of different mouthrinses on de novo plaque formation. J Contemp Dent Pract. 2012;13(4):460-3.

18. Agarwal P, Nagesh L. Comparative evaluation of efficacy of $0.2 \%$ Chlorhexidine, Listerine and Tulsi extract mouth rinses on salivary Streptococcus mutans count of high school children-RCT. Contemp Clin Trials. 2011;32(6):802-8

19. Allen DR, Davies R, Bradshaw B, Ellwood R, Simone AJ, Robinson R, et al. Efficacy of a mouthrinse containing $0.05 \%$ cetylpyridinium chloride for the control of plaque and gingivitis: a 6-month clinical study in adults. Compend Contin Educ Dent (Jamesburg, NJ : 1995). 1998;19(2 Suppl):20-6.

20. Kozak KM, Gibb R, Dunavent J, White DJ. Efficacy of a high bioavailable cetylpyridinium chloride mouthrinse over a 24-hour period: a plaque imaging study. Am J Dent. 2005;18 Spec No:18A-23.

21. Witt J, Bsoul S, He T, Gibb R, Dunavent J, Hamilton A. The effect of toothbrushing regimens on the plaque inhibitory properties of an experimental cetylpyridinium chloride mouthrinse. J Clin Periodontol. 2006;33(10):737-42.

22. Silva MF, dos Santos NB, Stewart B, DeVizio W, Proskin HM. A clinical investigation of the efficacy of a commercial mouthrinse containing $0.05 \%$ cetylpyridinium chloride to control established dental plaque and gingivitis. J Clin Dent. 2009;20(2):55-61.

23. Hu D, Li X, Sreenivasan PK, DeVizio W. A randomized, double-blind clinical study to assess the antimicrobial effects of a cetylpyridinium chloride mouth rinse on dental plaque bacteria. Clin Ther. 2009;31(11):2540-8.

24. He S, Wei Y, Fan X, Hu D, Sreenivasan PK. A clinical study to assess the 12-hour antimicrobial effects of cetylpyridinium chloride mouthwashes on supragingival plaque bacteria. J Clin Dent. 2011;22(6):195-9.

25. Schaeffer LM, Szewczyk G, Nesta J, Vandeven M, Du-Thumm L, Williams MI, et al. In vitro antibacterial efficacy of cetylpyridinium chloride-containing mouthwashes. J Clin Dent. 2011;22(6):183-6.

26. ten Cate JM. The need for antibacterial approaches to improve caries control. Adv Dent Res. 2009;21(1):8-12.

27. Gilbert P, McBain A, Sreenivasan P. Common therapeutic approaches for the control of oral biofilms: microbiological safety and efficacy. Clin Microbiol Infect. 2007;13 Suppl 4:17-24.

28. Buzalaf MA, Pessan JP, Honorio HM, ten Cate JM. Mechanisms of action of fluoride for caries control. Monogr Oral Sci. 2011;22:97-114.

29. ten Cate JM. Contemporary perspective on the use of fluoride products in caries prevention. Br Dent J. 2013;214(4):161-7.

30. Bradshaw DJ, Marsh PD, Hodgson RJ, Visser JM. Effects of glucose and fluoride on competition and metabolism within in vitro dental bacterial communities and biofilms. Caries Res. 2002;36(2):81-6.

31. Pitts N, Duckworth RM, Marsh P, Mutti B, Parnell C, Zero D. Post-brushing rinsing for the control of dental caries: exploration of the available evidence to establish what advice we should give our patients. Br Dent J. 2012;212(7):315-20.

32. Zero DT, Fu J, Espeland MA, Featherstone JD. Comparison of fluoride concentrations in unstimulated whole saliva following the use of a fluoride dentifrice and a fluoride rinse. J Dent Res. 1988;67(10):1257-62.

33. Duckworth RM, Maguire A, Omid N, Steen IN, McCracken Gl, Zohoori FV. Effect of rinsing with mouthwashes after brushing with a fluoridated toothpaste on salivary fluoride concentration. Caries Res. 2009;43(5):391-6.

34. Moi GP, Tenuta LM, Cury JA. Anticaries potential of a fluoride mouthrinse evaluated in vitro by validated protocols. Braz Dent J. 2008;19(2):91-6.

35. Patra JK, Kim ES, Oh K, Kim HJ, Kim Y, Baek KH. Antibacterial effect of crude extract and metabolites of Phytolacca americana on pathogens responsible for periodontal inflammatory diseases and dental caries. BMC Complement Altern Med. 2014;14:343.

36. Randall J, Seow W, Walsh L. Antibacterial activity of fluoride compounds and herbal toothpastes on Streptococcus mutans: An in vitro study. Australian dental journal. 2014. doi:10.1111/adj.12247.

37. Evans A, Leishman SJ, Walsh LJ, Seow WK. Inhibitory effects of children's toothpastes on Streptococcus mutans, Streptococcus sanguinis and Lactobacillus acidophilus. Eur Arch Paediatr Dent. 2015;16(2):219-26.

38. Park SN, Lim YK, Freire MO, Cho E, Jin D, Kook JK. Antimicrobial effect of linalool and alpha-terpineol against periodontopathic and cariogenic bacteria. Anaerobe. 2012;18(3):369-72.

39. Bradshaw DJ, Marsh PD, Allison C, Schilling KM. Effect of oxygen, inoculum composition and flow rate on development of mixed-culture oral biofilms. Microbiology. 1996;142(Pt 3):623-9.

40. Hope CK, Clements D, Wilson M. Determining the spatial distribution of viable and nonviable bacteria in hydrated microcosm dental plaques by viability profiling. J Appl Microbiol. 2002;93(3):448-55.

41. Ledder RG, Latimer J, Humphreys GJ, Sreenivasan PK, McBain AJ. Bacteriological effects of dentifrices with and without active ingredients of natural origin. Appl Environ Microbiol. 2014;80(20):6490-8.

42. Shiloh MU, Ruan J, Nathan C. Evaluation of bacterial survival and phagocyte function with a fluorescence-based microplate assay. Infect Immun. 1997;65(8):3193-8.

43. Netuschil L, Reich E, Unteregger G, Sculean A, Brecx M. A pilot study of confocal laser scanning microscopy for the assessment of undisturbed dental plaque vitality and topography. Arch Oral Biol. 1998;43(4):277-85.

44. Ledder RG, McBain AJ. An in vitro comparison of dentifrice formulations in three distinct oral microbiotas. Arch Oral Biol. 2012;57(2):139-47.

\section{Submit your next manuscript to BioMed Central and take full advantage of:}

- Convenient online submission

- Thorough peer review

- No space constraints or color figure charges

- Immediate publication on acceptance

- Inclusion in PubMed, CAS, Scopus and Google Scholar

- Research which is freely available for redistribution 